\title{
Distribution of the cestode Taenia parva (Taeniidae) along the digestive tract of the common genet (Genetta genetta)
}

\author{
A. RIBAS $^{1,2}$, C. FELIU ${ }^{2}$, J. C. CASANOVA ${ }^{2}$
}

\begin{abstract}
${ }^{1}$ INRA, UMR CBGP (INRA / IRD / Cirad / Montpellier SupAgro), Campus international de Baillarguet, CS 30016, F-34988 Montferrier-sur-Lez cedex, France, E-mail: aribas@ub.edu; ${ }^{2}$ Laboratory of Parasitology, Faculty of Pharmacy, University of Barcelona, Av. Diagonal s/n. 08028 Barcelona, Spain
\end{abstract}

\begin{abstract}
Summary
The small intestine of the common genet is the habitat of Taenia parva (Taeniidae), a common parasite whose intermediate host is Apodemus spp. (Rodentia). Here we divided the small intestine of 51 common genets into sections and analysed them separately. Cestodes were classified into four categories: larval, pre-adult, adult and gravid specimens. A total of 4,443 individuals were recovered and classified: 543 larval stages, 2,326 pre-adults, 872 adults and 702 gravid specimens. A double analysis was performed by checking the distribution of the parasite along the digestive tract and comparing this distribution with reproductive fitness. This is the first study to test the border effect on the distribution of T. parva in its habitat. We also tested and demonstrated the Ideal Free Distribution Model (IFM model). A non-random distribution was found, with the lowest parasite frequencies in the top and the bottom portions of the small intestine. Maturity classes of cestodes vs. intestine portion were tested and no differences between portions were detected. We also analysed seasonal changes in parasite frequency. Log-linear analysis showed that the mean frequency of cestode occurrence per individual host was higher during winter, followed by spring, autumn and summer.
\end{abstract}

Keywords: edge effect; Genetta genetta; habitat selection; parasites; site preference; Taenia parva

\section{Introduction}

The use of parasitic helminths to test habitat selection has the advantage that habitats are replicated in each host, while these replicas cannot be achieved with such accuracy in free-living environments. Intraspecific competition is reduced if the entire habitat is used (see review by Sukhedeo \& Bansemir, 1996). Models of ectoparasites on fish gills demonstrated that competition for food and space does not adequately explain habitat specificity (Sukhedeo
\& Bansemir, 1996). These authors also reported that parasite restriction to specific habitats increases intraspecific contact and facilitates mating. The Ideal Free Distribution Model (IFM model) (Fretwell \& Lucas, 1970) postulates how animals distribute in an environment with areas of distinct habitat quality. If all habitats are of equal quality, a homogeneous distribution would be expected. Therefore, applying this notion to parasitology, we would expect a homogenous distribution of a parasite throughout a given microhabitat (e.g. the small intestine).

Helminths do not show a non-random distribution along the intestinal tract (Sukhedeo \& Bansemir, 1996). This observation could be attributed to the non-homogeneous habitat provided by the small intestine as the morphological and chemical characteristics vary along its length. The nematode Heligmosomoides polygyrus (Dujardin, 1845) shows preference for the part of the intestine nearest to bile entry (Sukhedeo \& Bansemir, 1996). Furthermore, the rates of helminth reproduction differ along the intestine, as shown for the nematode Trihinella spiralis (Owen, 1835). Here we have integrated these two concepts to simultaneously test parasite distribution along small intestine and reproductive success.

While intraspecific competition has been reported in rodents (Sukhedeo \& Bansemir, 1996), the present study is the first related to carnivores.

Genetta genetta (L. 1758) (Carnivora, Viverridae) is distributed throughout Africa, the Arabian Peninsula and southwestern Europe (Calzada, 2007). In south-western Europe, the common genet is assumed to have been introduced from North Africa by Man (Calzada, 2007). The earliest known remains of common genet in Europe date to the Middle Ages (Morales, 1994). The common genet and the wood mice are a binomy in the Iberian Peninsula because they share the same habitats (forestal Mediterranean habitats). In the Iberian Peninsula, the life cycle of T. parva is exclusive between Apodemus sylvaticus L, 1758 and 
Apodemus flavicollis (Melchior, 1834, and the common genet, as intermediate (larvae in abdominal cavity) and definitive hosts, respectively (Casanova et al., 2000). T. parva is a frequent parasite of Apodemus spp. in the study area (Ribas et al., 2004).

Several authors (Mostefai et al., 2003 in North Africa and Arrizabalaga et al., 2002 in Spain) have reported that the common genet feeds mainly on Apodemus spp. This finding is reinforced by the high prevalence of T. parva (90.9 $\%$ ) in genet populations in Spain (Casanova et al., 2000). We hypothesize that the small intestine of $G$. genetta is at its maximum capacity of $T$. parva because of constant ingestion of parasitized Apodemus spp. Given that the habitat occupied by $T$. parva is at its maximum capacity, the output (reproductive fitness) should be the same in all individuals located in that habitat (in this case different portions of the intestine).

As the small intestine of the studied carnivore is the habitat of T. parva we should expect a symmetrical (according to the IFM model) or an asymmetrical distribution of parasites along the small intestine, as was previously found in rodent studies (Sukhedeo \& Bansemir, 1996).

\section{Material and methods}

A total of 51 genets were collected from the Montseny Natural Park and proximities between 1991 and 1995 (winter $\mathrm{n}=18$, spring $\mathrm{n}=9$, summer $\mathrm{n}=2$, autumn $\mathrm{n}=$ 11). Digestive tracts were removed and frozen until dissection. For dissection, the small intestine was divided into seven sections of equal length, each of which was examined separately.
Table 1. Results of the log-linear analysis of cestode frequency per individual host by season, intestinal section, and maturity, with the two-way and three-way interactions also shown

\begin{tabular}{lccc}
\hline Effects & $\begin{array}{c}\text { Degrees } \\
\text { of freedom }\end{array}$ & $\mathrm{G}$ & $\mathrm{p}$ \\
\hline Season & 3 & 81.7101746 & 0.0000 \\
Section & 6 & 19.3246002 & 0.0037 \\
Maturity & 3 & 50.7341461 & 0.0000 \\
Season x Section & 18 & 30.4849873 & 0.0330 \\
Season x Maturity & 9 & 37.1785431 & 0.0000 \\
Section x Maturity & 18 & 10.5394058 & 0.9128 \\
Season x Section x Maturity & 54 & 19.27 & 0.9999 \\
\hline
\end{tabular}

All the intestines harboured T. parva, which were collected and transferred to $70 \%$ alcohol for later identification of sexual stage. Cestodes were classified into four categories: larval (genitalia not developed); pre-adult (genitalia development and lack of eggs); adult (genitalia fully developed and some eggs in last segments); and gravid specimens (plenty of eggs in a conformed uterus).

Statistical log-linear analysis (Zar, 1996) was used to test for differences in the frequencies of occurrence of cestodes according to their degree of maturity (larval, pre-adult, adult and gravid), season, and intestine section $(\mathrm{n}=7)$, and their interactions. The statistical significance within levels of a factor was verified by examining the components of maximum likelihood and comparing these values with the critical level of significance for 1 degree of freedom $\left(\mathrm{Chi}^{2}\right.$ $=3.84, P<0.05)$ (López-Darias et al., 2008).
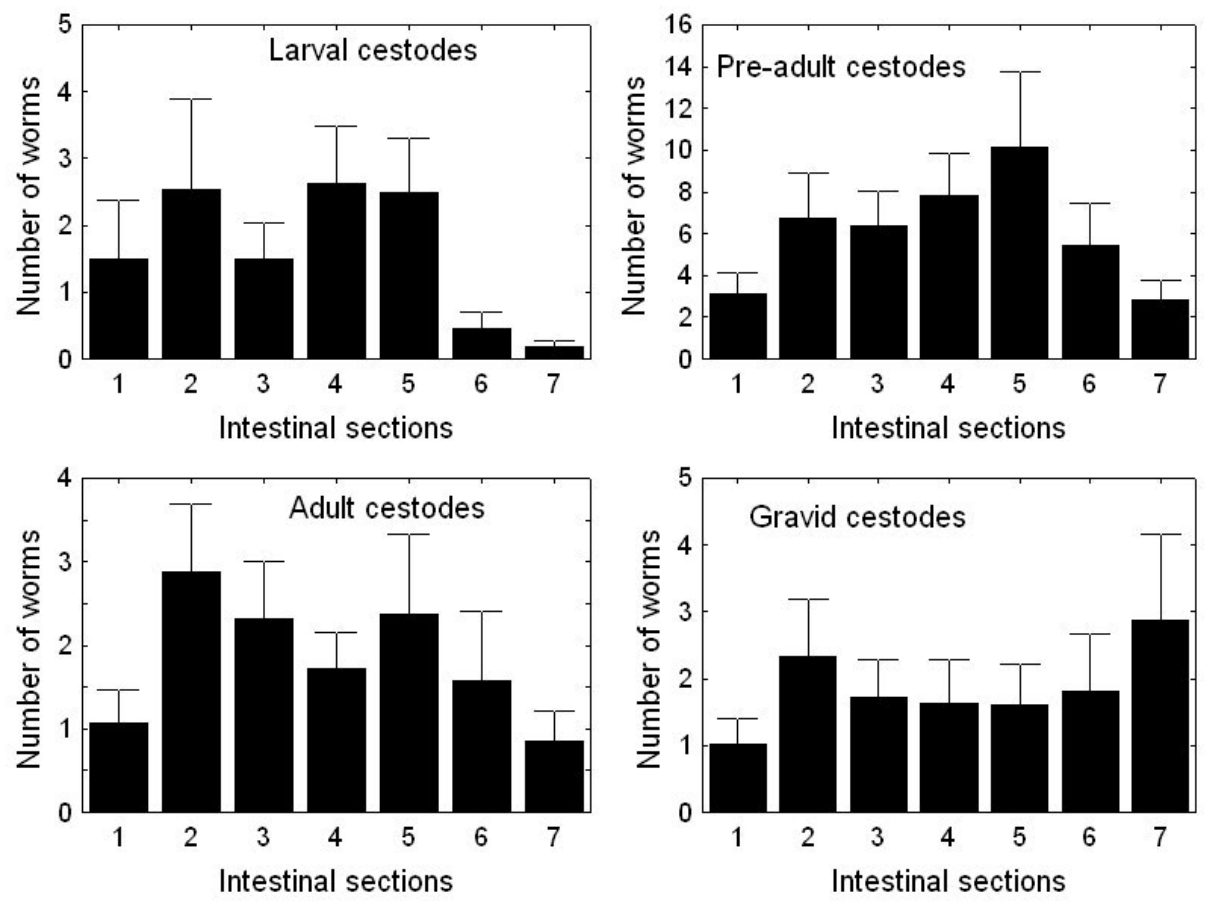

Fig. 1. Number of cestodes by maturity class and intestinal section. Mean ( \pm standard deviation). 


\section{Results}

A total of 4,443 individuals were recovered and classified: 543 larval stages, 2,326 pre-adults, 872 adults and 702 gravid specimens.

Log-linear analysis (Table 1) showed that the mean frequencies of cestode occurrence per individual host were higher during winter, followed by spring, autumn and summer $\left(\mathrm{G}_{3}=81.71, \mathrm{p}<0.0001\right)$.

Pre-adult cestodes were the dominant class, accounting for $53.39 \%$ of the individuals identified, while the other three classes had similar frequencies $\left(14.18-16.32 \%, \mathrm{G}_{3}=\right.$ 50.73, $\mathrm{p}<0.0001)$.

Cestodes were unevenly distributed along intestinal sections $\left(\mathrm{G}_{6}=19.32, \mathrm{p}=0.003\right)$. Section 5 had the highest frequency $(20.91 \%)$, whereas sections 1 and 7 had the lowest $(8.45 \%$ and $8.42 \%$, respectively).

The two-way interactions indicated that season had a significant effect on the occurrence of individuals amongst maturity classes and intestinal sections. Larval cestodes were more frequent during spring, but pre-adult, adult and gravid categories were more frequent during winter, with intermediate values in the other seasons $\left(\mathrm{G}_{9}=37.17, \mathrm{p}<\right.$ $0.0001)$. Despite the low sample size for the summer $(\mathrm{n}=$ 2), during this season gravid individuals were more frequent than the other classes.

The interaction between season and section indicated that the distribution of individuals along sections of the intestine varied depending on the season $\left(\mathrm{G}_{18}=30.48, \mathrm{p}=\right.$ $0.033)$.

In contrast, a lack of interaction between section and maturity indicated no association of maturity classes with intestinal sections $\left(\mathrm{G}_{18}=10.53, \mathrm{p}<0.91\right)$ (see Fig. 1 ).

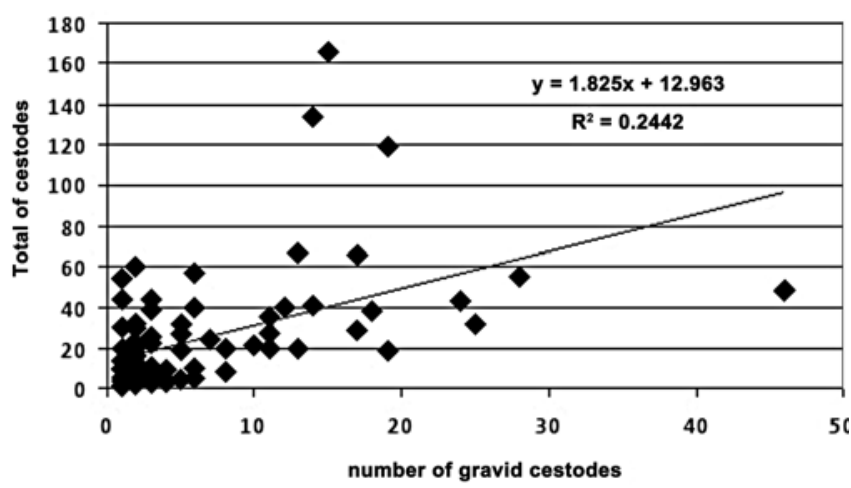

Fig. 2. Relationship between number of gravid cestodes vs total cestodes

Finally, the lack of the three way interaction indicated that the distribution of individuals of all maturity classes was independent of season and of intestinal section $\left(\mathrm{G}_{54}=\right.$ 19.27, $\mathrm{p}<0.99$ ).

A positive correlation $(\mathrm{r}=0.521)$ between number of gravid cestodes vs. total cestodes was found (Fig. 2).

\section{Discussion}

We detected a non-random distribution of the cestodes along the small intestine of the genet, with the lowest fre- quencies in the upper and lower sections (sections 1 and 7). This observation may reflect the instability of habitat as a result of border effect (contact with the stomach on one side and the large intestine on the other). Border effect can be defined as any change in the distribution of a variable as a consequence of a transition between habitats (Lidicker, 1999; Lidicker \& Peterson, 1999). This is the first time that this ecological term has been applied to parasitology. Ecotone effect has been studied intensively in free-living organisms, animals (Stevens \& Husband, 1998) and plants (Matlack, 1994; Lopez de Casanove et al., 1995; Gehlhausen et al., 2000); however, parasitological approaches have not been performed.

The absence of a significant effect on the occurrence of individuals amongst maturity classes and intestinal sections contrasts with the findings of other studies (Sukhedeo \& Bansemir, 1996). This discrepancy can be attributed to the presence of physiological conditions required by cestodes to reach maturity along the entire small intestine.

The dominance of pre-adult stages $(53.39 \%)$ may be a consequence of the longer life span of this stage compared with other stages.

Seasonal changes in cestode abundance were also observed. High occurrence of cestodes per individual during winter could be attributed to the alimentary strategy of the host. In winter Apodemus spp. is the main prey of $G$. genetta as at this time of the year other resources such as fruit, chickens and arthropods, are not available. This variability in the common genet's diet has been described elsewhere (Arrizabalaga et al., 2002). Moreover, mice born in spring and autumn will become adults in winter, thereby increasing their probability of acquiring the parasite. The highest frequency of larval cestodes during spring can be correlated with greater activity of Apodemus spp., which in turn increases the risk of infection and also the risk of being preyed upon. However, pre-adult, adult and gravid cestodes were more frequent during winter, with intermediate values in the other seasons. Despite the low sample size for summer $(n=2)$, during this season gravid individuals were more frequent than the other classes, which were few. This observation is attributed to larval stages from spring having involved to adult individuals.

A non-crowding effect was found without a decrease in fertility when parasite loads increased. This finding could be explained by non-saturation of habitat, or, taking into account the IFM, the parasite may occupy the free habitats of the intestine.

Despite present work adds new data on the distribution of helminths along the intestinal tract, future studies are required to increase knowledgment on habitat selection of helminths.

\section{Acknowledgments}

We thank Dr. Ignacio Torre at the "Museu de GranollersCiències Naturals" for his advice and help with the statistical analysis. 


\section{References}

Arrizabalaga, A., Flaquer, C., Ribas, A., Torre, I. (2002): Noves dades sobre la dieta del gat mesquer (Genetta genetta) al Montseny. Monografies 33: 85 - 88 CAlZADA, J. (2007): Genetta genetta (Linnaeus, 1758) In: Palomo, L. J., Gisbert J., Blanco, J. C. (Eds): Atlas y Libro Rrojo de los mamíferos terrestres de España. Dirección General de Conservación de la Naturaleza - SECEM SECEMU, Madrid

Casanova, J. C., Feliu, C., Miquel, J., Torres, J., ŠPAKULOVÁ, M. (2000): Faunistic and ecological trends on the helminth community of Genetta genetta Linnaeus, 1758 (Carnivora: Viverridae) in the Iberian Peninsula. Helminthologia 37: $223-228$

FreTWELL S. D., LUCAS, H. L. (1970): On territorial behaviour and other factors influencing habitat distribution in birds. Acta Bio. Theor., 19: 16 - 36

Gelhausen, S. M., Schwartz, M. W., Augspurger, C. K. (2000): Vegetation and microclimatic edge effects in two mixed-mesophytic forest fragments. Plant Ecol., 147: $21-35$

LIDICKER, W. Z. J. (1999): Responses of mammals to habitat edges: an overview. Landscape Ecol., 14: 333 343

Lidicker, W. Z. J., Peterson, J. A. (1999): Responses of small mammals to habitat edges. In: BARRETT, G.W., PELES, J. D. (Eds) Landscape Ecology of Small Mammals, Springer-Verlag, Berlin

Lopez De Casanave, J., Pelotto, J. P., Protomastro, J. (1995): Edge-interior differences in vegetation structure

RECEIVED JULY 7, 2008 and composition in a Chaco semi-arid forest, Argentina. Forest Ecol. Manag., 72: 61 - 69

Lopez-Darias, M., Ribas, A., Feliu C. (2008): Parasites comparison of native and invasive mammal populations: helminth fauna of the Barbary ground squirrel (Atlantoxerus getulus Linnaeus, 1758; Rodentia, Sciuridae) Acta Parasitol., 53(3): 296 - 301

MATLACK, G. R. (1994). Vegetation dynamics of the forest edge - trends in space and successional time. J. Ecol., 82: $113-123$

Mostefai N., Sellami M., Grenot C. (2003): Contruibution à la connaissance du régime alimentarie de la genette commune (Genetta genetta) dans la réserve cynéegétique de Moutas, Tlemcen (Algerie) Bull. Soc. Zool. Fr., 128: $227-237$

Morales, A. (1994): Earliest genets in Europe. Nature (London), 370: 512 - 513

Ribas, A., Casanova, J.C., Goüy De BellocQ, J., Feliu, C. (2004): Helminth fauna of a sympatric population of Apodemus sylvaticus and A. flavicollis (Rodentia, Muridae) in Natural Park of Montseny (Spain), IX European Multicolloquium of Parasitology, Valencia

Stevens, S. M., Husband, T. P. (1998): The influence of edge on small mammals: evidence form Brazilian Atlantic forest fragments. Biol. Conserv., 85: $1-8$

SukhedeO, M. V. K., Bansemir A. D. (1996): Critical resources that influence Habitat Selection decisions by gastrointestinal helminth parasites. Int. J. Parasitol. 26: $483-498$

ZAR, J. H. (1996): Biostatistical Analysis. Prentice Hall, London 